\title{
The Analysis and Comparison of All Kinds of Buried Pipeline Model Based on Seismic Effect
}

\author{
Xiaoli Li' ${ }^{1}$, Jing Sun ${ }^{2}$, Tinghui Li ${ }^{1}$ \\ ${ }^{1}$ College of Civil and Architecture Engineering, Northeast Petroleum University School, Daqing, China \\ ${ }^{2}$ China Electric Power Press LTD, Beijing, China \\ Email:35143799@qq.com,30443699@qq.com
}

Received 2 June 2016; accepted 21 June 2016; published 24 June 2016

Copyright (C) 2016 by authors and Scientific Research Publishing Inc.

This work is licensed under the Creative Commons Attribution International License (CC BY). http://creativecommons.org/licenses/by/4.0/

c) (i) Open Access

\section{Abstract}

The problem of seismic response of buried pipeline aimed at the interaction of soil around the pipeline and the complicated calculation model was considered, and the various simplified finite element model was calculated, and it was analyzed. Firstly, the ADINA finite element analysis software was used. The four nodes in shell unit were used by tube. The spring unit was used by soil spring. The analysis model of buried pipeline finite element numerical based on tension and compression spring was established. Seismic wave was input. The response to the simple boundary, viscoelastic boundary earthquake were calculated and analyzed by the finite element numerical simulation. The pipeline's earthquake ground motion response was obtained, and was compared with the real soil model, and the most suitable simplified calculation model for numerical analysis of buried pipeline was found, which was the numerical analysis model of buried pipeline pressure spring tension finite element based on the viscoelastic boundary, and the theory basis for the seismic design of pipeline was provided.

\section{Keywords}

Buried Pipeline, Viscoelastic Boundary, Tension and Compression Spring

\section{Introduction}

Pipeline transportation is the main means of energy transportation, and it is the lifeline engineering of modern society. China is an earthquake prone country [1] [2], buried pipeline as an important part of the long pipeline project that is inevitable to be built in the earthquake prone area. Now the experts and scholars of domestic and 
foreign on the seismic response laws of buried pipeline have been done a large number of studies [3]-[5]. The commonly used pipe soil mutual interaction models are: elastic foundation beam model [6], soil spring model [7] and nonlinear contact model [8]. The spring soil analysis model of buried pipeline in tension and compression on viscoelastic boundary was established by being used ADINA finite element analysis software on the basis of previous research in this paper [9]-[12]. The buried pipeline seismic response was analyzed, and it was compared with the simple boundary model or entity model of soil to be found the optimal simplified model, which had certain guiding significance for the actual pipeline seismic design.

\section{Finite Element Implementation of Buried Pipeline Model with Tension and Compression Spring}

\subsection{The Selection of the Unit}

The pipe body was adopted the four node shell unit because the buried pipeline was a three-dimensional modeling. The soil around the buried pipeline was replaced by soil spring, the spring unit was chosen when being modelled in ADINA. The nonlinear analysis was carried out, and the tension spring was used to simulate the soil spring. The nonlinear properties were needed to open the panel, and the appropriate force displacement relation and the parameters of the nonlinear elastic material were set up.

\subsection{Determination of Material Parameters}

The Q235 was selected as the pipeline steel in this paper, the curves of experiment of simplified bilinear stress-strain relationship was used in ADINA finite element software. The interaction between in soil and pipe was simulated through three directional nonlinear spring, and the soil spring was included three direction (axis, horizontal, vertical). The pipe body was adopted four node shell elements, and was used steel pipes, pipe diameter was equal to 0.764 meter, pipeline wall thickness was equal to 0.01 meter, the burial depth of the pipe was equal to 2 meter, Young's modulus was equal to $\mathrm{E}=2.1 \mathrm{e} 11 \mathrm{pa}$, density was equal to $\rho=7800 \mathrm{~kg} / \mathrm{m}^{3}$, poisson's ratio was equal to $\mu=0.3$, it was above underground water level, and it was soil type in IV site.

\subsection{Seismic Wave}

The seismic waves of El Centro were used, the duration time of the earthquake was 10 second. The time interval was 0.02 second. As shown in Figure 1 and Figure 2, the seismic waves were horizontally input in order to be

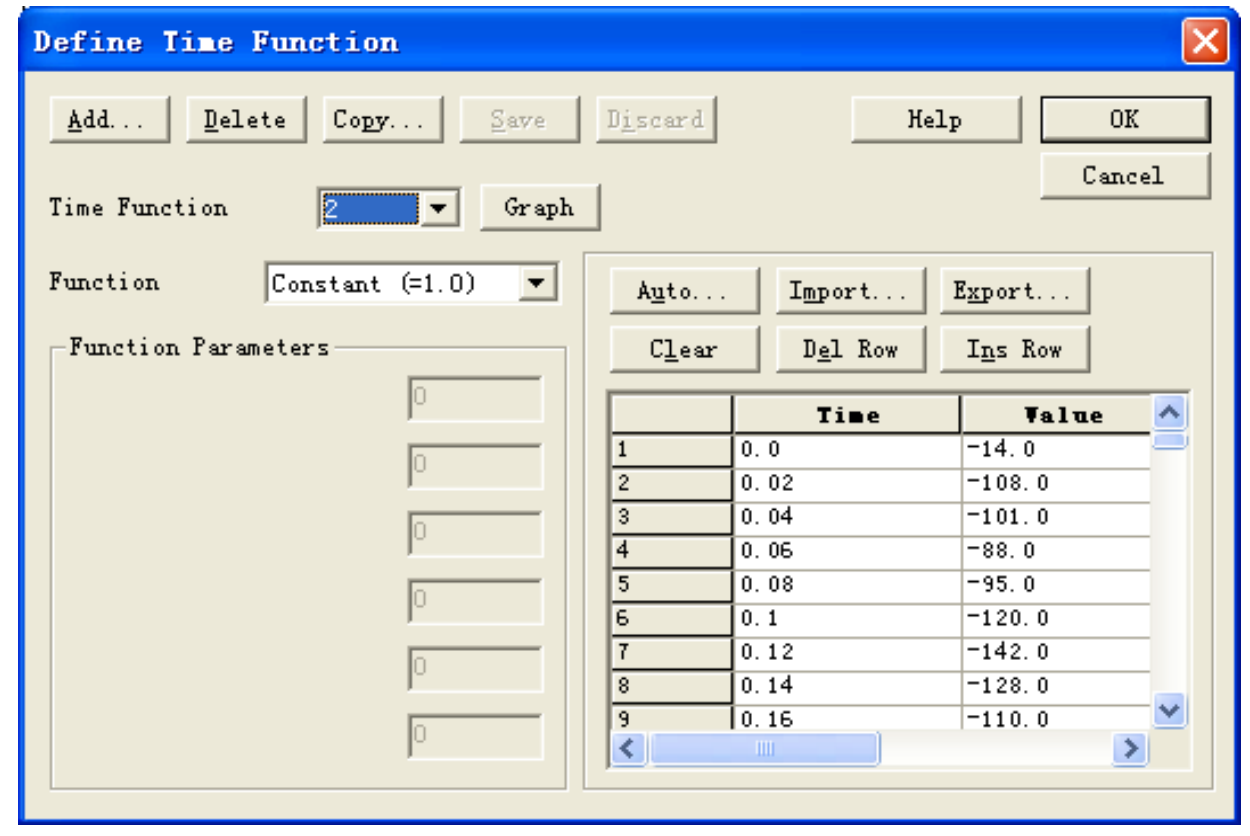

Figure 1. El Centro acceleration record chart. 


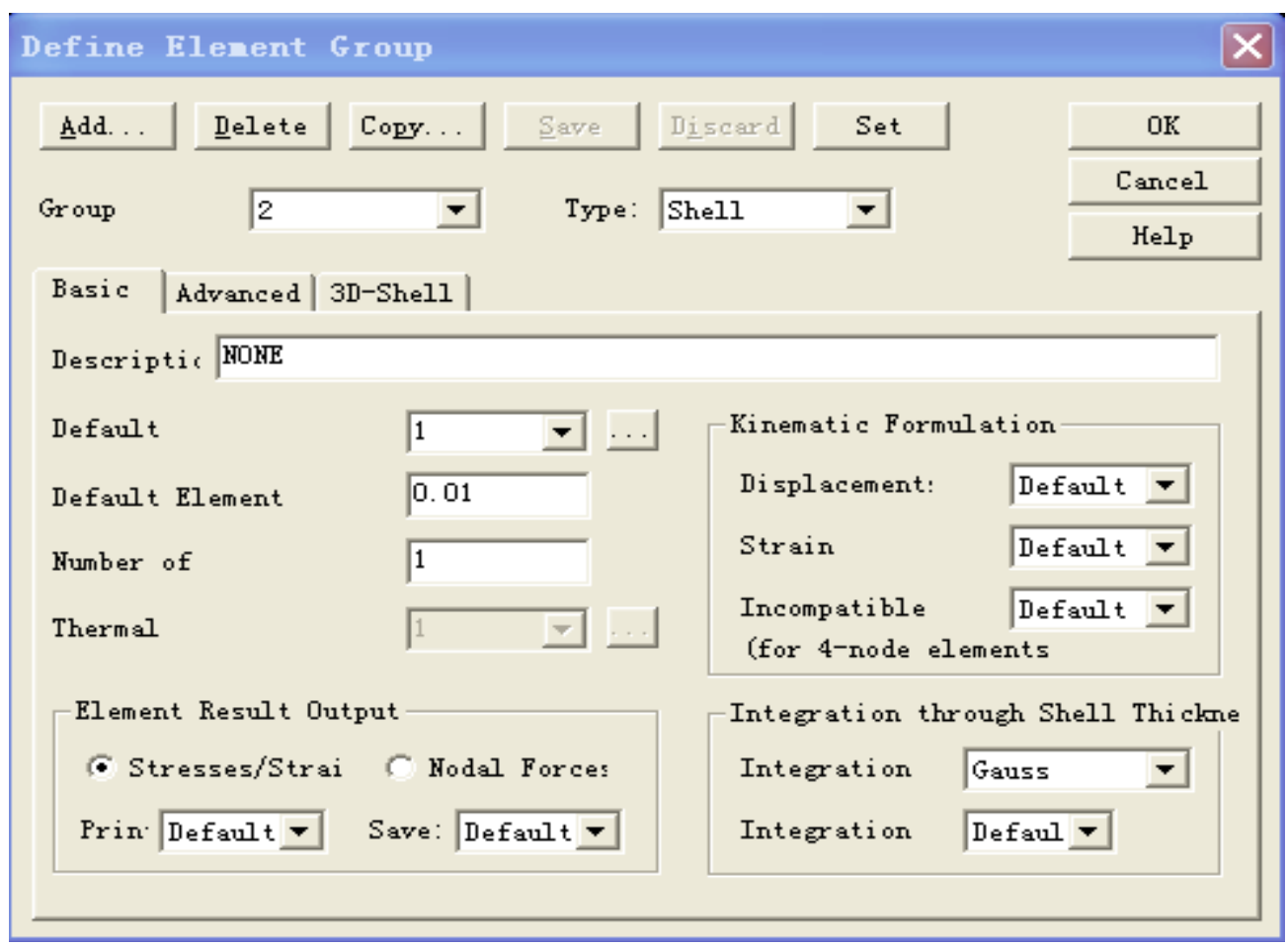

Figure 2. Shell unit.

considered the effect of ground motion of different intensity. This wave was had a high magnitude, and it was more suitable to be used as a design basis than other seismic waves. The input was adjusted according to the requirement of the 8 degree earthquake, seismic acceleration records were from north to south.

\section{The Determination of Effective Area of Viscoelastic Boundary Model}

\subsection{The Simulation Method of Viscoelastic Boundary in ADINA}

The viscoelastic boundary could be implemented in ADINA, which was a linear single degree of freedom spring damping unit in ADINA. In this spring, the stiffness matrix and damping matrix of the ground spring were all one-dimensional.

\subsection{The Determination of Effective Area of Viscoelastic Boundary Model}

Simple boundary: Fixed boundary was used in both ends of pipeline;

Viscoelastic boundary: Spring damper unit was adopted in the two ends of the pipe.

The pipeline was used four node Shell unit, as shown in Figure 3. The pipeline was divided into unit grids along the pipeline circumferential and axial direction, as shown in Figure 4. The circumferential direction of the pipe was divided into 16 units.

Viscoelastic boundary: The seismic response displacement and response stress of the pipeline length of $30 \mathrm{~m}$, $40 \mathrm{~m}, 60 \mathrm{~m}$ and $80 \mathrm{~m}$ were calculated and analyzed.

As shown in Table 1, the maximum horizontal displacement and the maximum compressive stress of the buried pipeline were increased with the increase of the pipe length. With the increase of the calculation range, it was tended to be stable. When the range of calculating was increased to $60 \mathrm{~m}$, it was basically stable, and was approximately $60 \mathrm{~d}$. So we were in the calculation area of the viscoelastic boundary, the pipe length was $60 \mathrm{~m}$.

\subsection{The Comparative Analysis of Calculation Results of Simple Boundary and Viscoelastic Boundary Pipeline Model}

Centro El acceleration wave in horizontal direction was introduced, and the difference between the simple 


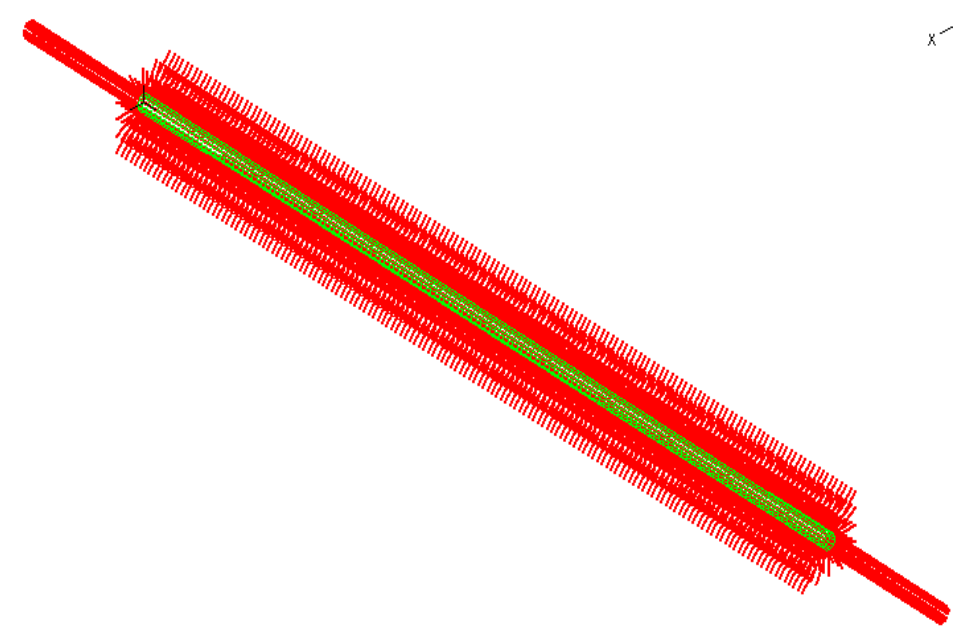

Figure 3. Viscoelastic boundary of soil spring model of underground.

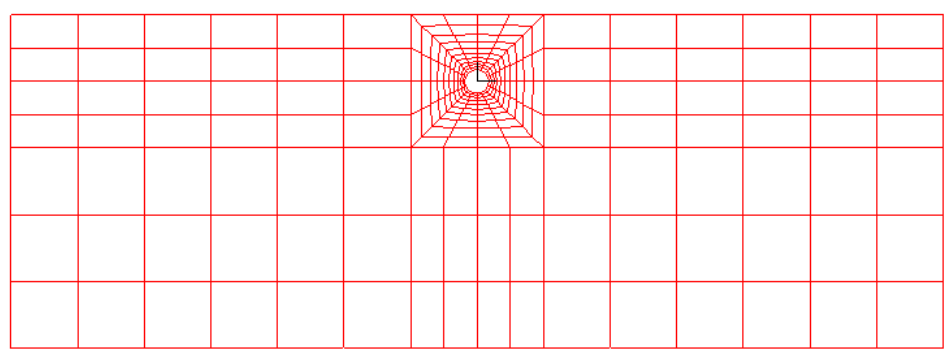

Figure 4. The solid soil model.

Table 1. Comparative analysis of the maximum horizontal displacement force effect of different length of buried pipelines under earthquake and the maximum compressive stress.

\begin{tabular}{ccc}
\hline Pipe length $(\mathrm{m})$ & $\begin{array}{c}\text { Maximum horizontal } \\
\text { displacement }(\mathrm{m})\end{array}$ & $\begin{array}{c}\text { maximum compressive stress } \\
(\mathrm{pa})\end{array}$ \\
\hline 30 & 0.005165 & $2,635,972$ \\
40 & 0.005184 & $3,441,374$ \\
60 & 0.005204 & $3,827,513$ \\
80 & 0.005214 & $3,773,118$ \\
\hline
\end{tabular}

boundary and the viscoelastic boundary pipeline and the soil mass was observed.

\subsection{The Solid Soil Model}

The solid modeling was used in the soil, as shown in Figures 4-6. Although it was relatively time consuming, the relative efficiency was relatively low, but the calculation result was relatively reliable. In this paper, the ADINA software was used to establish the solid model of the buried pipeline, and the pipeline length was 60 meters. The purpose of this paper was to compare the numerical results of the finite element model of the buried pipeline with the finite element model of the buried pipeline.

\subsection{The Comparative Analysis of Calculation Results of Solid Soil Model, Simple Boundary and Viscoelastic Boundary Pipeline Model}

As shown in Table 2, the calculation results of solid soil model, simple boundary and viscoelastic boundary pipeline model are compared and analyzed. 


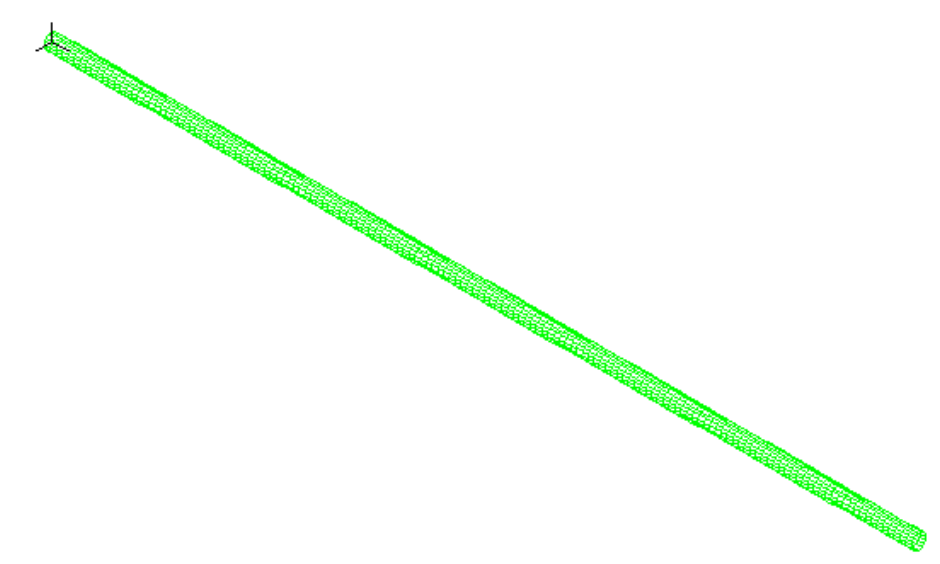

Figure 5. Finite element model of buried pipeline.

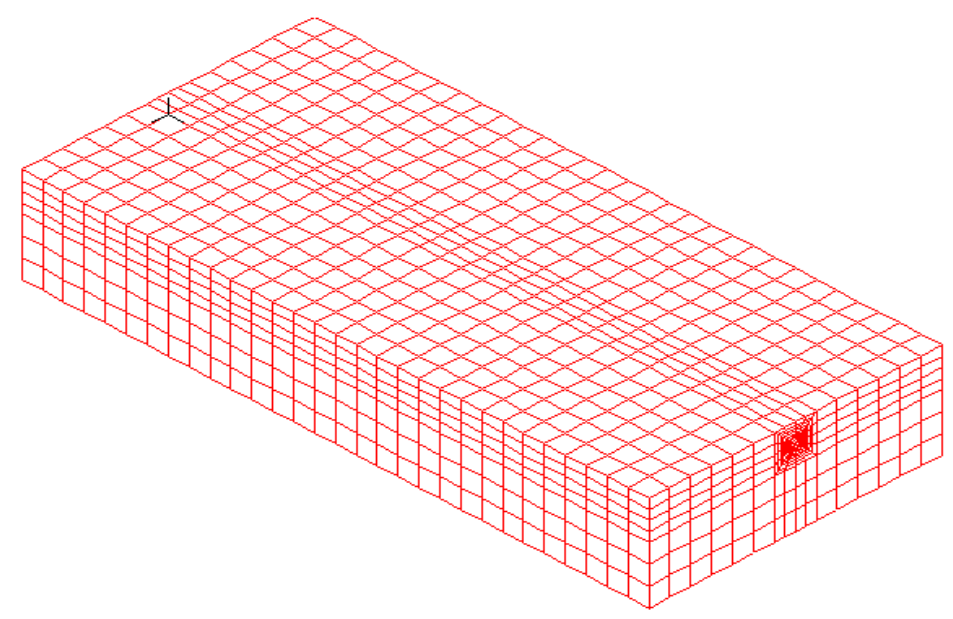

Figure 6. Finite element model of soil.

Table 2. Horizontal pipe 27,694 node displacement and stress.

\begin{tabular}{ccc}
\hline type & $\begin{array}{c}\text { maximum horizontal } \\
\text { displacement }(\mathrm{m})\end{array}$ & $\begin{array}{c}\text { maximum compressive } \\
\text { stress }(\mathrm{pa})\end{array}$ \\
\hline $\begin{array}{c}\text { The entity } \\
\text { model of soil }\end{array}$ & 0.001675 & 970,931 \\
simple boundary & 0.004164 & $17,940,000$ \\
viscoelastic boundary & 0.005057 & $3,827,513$ \\
\hline
\end{tabular}

\section{Results and Discussions}

The finite element calculation model of the buried pipeline based on the viscoelastic boundary was established. By being based on the finite element analysis software ADINA, the calculation area of the buried pipeline with tension and compression spring based on the viscoelastic boundary under the action of Centro El acceleration wave was analyzed. It was concluded that the simplified calculation area was 60 times the diameter.

By being used ADINA finite element analysis software, the ground motion response of the pipeline under the action of the IV field and the seismic action was analyzed and compared with the simple boundary, the viscoelastic boundary and the solid pipeline model. It was found that it was more practical to simulate the effect of the tension spring and the soil of the solid earth. But the solid earth model was time consuming. The maximum compressive stress was much greater than the simple boundary entity model of viscoelastic soil boundary hori- 
zontal maximum compressive stress, which was larger error, and the viscoelastic boundary was achieved, and theoretical basis for seismic design of pipeline was provided.

\section{References}

[1] Li, G.Q. (1985) The Calculation Theory and Method of Seismic Structure. Seismological Press, Beijing, 65-68.

[2] Pan, C.S. (1990) Summary of Tunnel Seismic Disaster. The Tunnel and Underground Engineering, 11, 1-9.

[3] Wang, X.Z., Dong, F. and Liu, Y. (2012) Research Progress of Long Distance Pipeline Safety under the Action of Earthquake Disaster. Safety and Environmental Engineering, 18, 28-33. http://dx.doi.org/10.1016/j.ecoenv.2011.11.008

[4] Zhao, L. and Feng, Q.M. (2011) Research on Methods for Establishing FEM Model of Buried Pipelines. Earthquake Engineering and Engineering Vibration, 39, 43-46.

[5] Hang, G.W., Zhou, G.Q. and Liu, J.M. (2011) Heat-Structure Coupling of Dry Gas Compressor Outlet Based on Stress Analysis of Gas Transmission Pipeline. Fluid Machinery, 39, 43-46.

[6] Xiao, H.B., Ouyang, J.X., Wang, Y.H., et al. (2003) Finite Element Method Analysis of Variable Section Beam on Elastic Foundation. Journal of Zhuzhou Institute of Technology, 17, 96-100.

[7] Du, G.F. and Song, X. (2012) Buried Gas Pipeline Seismic Response Analysis of Numerical Simulation. Journal of Oil and Gas, 34, 157-160.

[8] Xu, L., Liu, J., Ye, Z.C., et al. (2012) Analysis of Factors Influencing underground Glass Steel Pipe with Sand Seismic Response. Glass Fiber Reinforced Plastic/Composite Materials, 6, 57-63.

[9] Zhao, Z.L., Jiao, G.W., et al. (2014) Buried Pipeline Seismic Response of Soil Spring Model Based on Numerical Simulation. Pressure Vessel, 31, 50-55.

[10] Liu, A.W. (2002) Analysis of Buried Pipeline Based on Seismic Shell Model. Research Institute of Geophysics, China Earthquake Administration.

[11] Jiang, B.F. (2012) City Direct Type Earthquake Seismic Response Analysis of Directly Buried Heating Pipeline under. Harbin Institute of Technology.

[12] Jing, L., Yi, X.D., et al. (2006) 3D Viscous-Spring Artificial Boundary in Time Domain. Earthquake Engineering and Engineering Vibration, 5, 93-102. http://dx.doi.org/10.1007/s11803-006-0585-2

\section{Submit or recommend next manuscript to SCIRP and we will provide best service for you:}

Accepting pre-submission inquiries through Email, Facebook, Linkedin, Twitter, etc

A wide selection of journals (inclusive of 9 subjects, more than 200 journals)

Providing a 24-hour high-quality service

User-friendly online submission system

Fair and swift peer-review system

Efficient typesetting and proofreading procedure

Display of the result of downloads and visits, as well as the number of cited articles

Maximum dissemination of your research work

Submit your manuscript at: http://papersubmission.scirp.org/ 